\title{
FEM Analysis of Robotized Arc Welded Joint
}

\author{
Anas Islam $^{1 *}$, Vijay Dwivedi ${ }^{1}$, Kamal Sharma ${ }^{1}$ \\ ${ }^{1}$ IET Department of Mechanical Engineering GLA University Mathura, India
}

\begin{abstract}
Welding is one of the most important phenomenon as far as the joining of two bodies are concerned. Welding processes are common in fabrication industries. Different types of welding are used in the automobile industries for the manufacturing of their bodies. Other examples of industries where welding plays a crucial role include construction industries, aviation industries, fabrication of pipelines, general repairing of machines, etc. As welding is such a most important factor in almost all industries, therefore it deserves proper attention in order to optimize the whole welding process. On one hand welding process is quite beneficial but on the other hand, it requires very careful attention of the operator, as there were several cases of accident due to welding just because of the carelessness of the operator. Also, it is a repetitive task so the labor or worker is engaged in working without proper use of their brains and in some other productive works. Thus, a number of manpower is only engaged for welding operation this makes the work boring and this restricts them from showing their true potential. This paper deals with the finite element analysis (FEA) of welded single V joint for obtaining the Shear Elastic Strain, Normal Elastic strain, Strain energy, and Shear stress respectively developed at the welded joint. The temperature of the weld pool taken for analysis is $400^{\circ} \mathrm{C}$ and the material of the specimen is Mild steel ASTM A 36 for welding and its coordinating filler material AWS A5.1 E 6013 were chosen in this study. The specimen size was $30 \times 150 \times 9 \mathrm{~mm}^{3}$ thickness. Welding current was set to $90 \mathrm{~A}$ with welding speed $27 \mathrm{~mm} / \mathrm{sec}$.
\end{abstract}

\section{Introduction}

An automated system has been developed with the help of an Aristo $^{\mathrm{TM}}$ robot, so as to have a robotized welding experience and to get the same quality of welding. A program has been made on the Application provided by the Aristo robot for assigning the weld path to the Manipulator arm of the robot. Forward and inverse kinematics have been applied at the backend for controlling the manipulator arm motion along with this Denavit-Hartenberg parameters (DH parameters) were employed for the purpose of the reference position of a kinematic chain of the manipulator arm of the robot.

The above is a common DH parameter matrix the $\theta$ denotes the angle between the links of the manipulator's $\mathrm{arm}$. The drawing of the V-groove was made on Solid works 2016 and the parts were assembled by weldment.

$$
[Z]=\left[\begin{array}{cccc}
\cos \theta_{i} & -\sin \theta_{i} & 0 & 0 \\
\sin \theta_{i} & \cos \theta_{i} & 0 & 0 \\
0 & 0 & 1 & d_{i} \\
0 & 0 & 0 & 1
\end{array}\right]
$$

The drawing of the $\mathrm{V}$-groove was made on Solid works 2016 and the parts were assembled by weldment joint thus a weld bead is created in the drawing as shown in Figure 1.

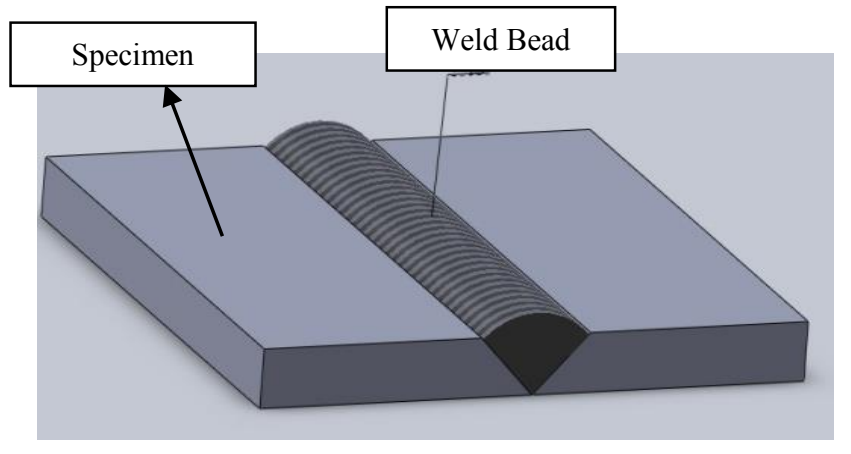

Fig. 1. Showing the weld bead of Single V Groove joint.

After making the assembly part on solid works its IGES format (geometry) is transferred to ANSYS 15.0 for the analysis purpose. The Figure 2 below illustrates the drawing of the specimen after transferred to the ANSYS 15.0.

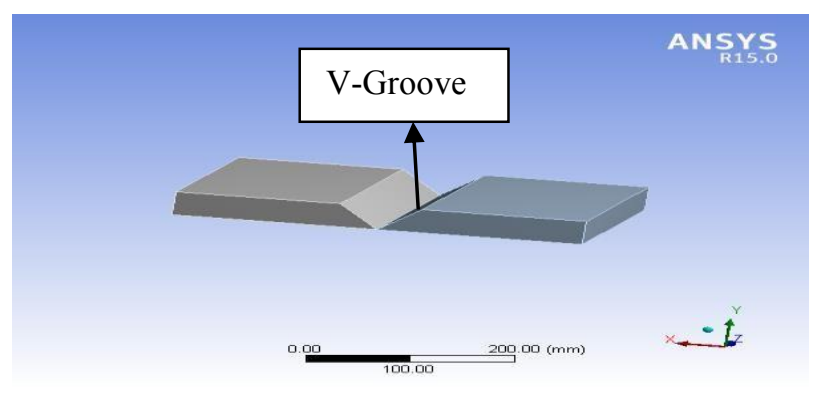

Fig. 2. Single V- Groove specimen for welding Analysis.

\footnotetext{
* Corresponding author: anasmechengg@gmail.com
} 
The finite element analysis (FEA) of welded single V joint is carried out for obtaining the Shear Elastic Strain, Normal Elastic strain, Strain energy and Shear stress respectively developed at the welded joint. The temperature of the weld pool taken for analysis is $400^{\circ} \mathrm{C}$ as found out by the thermocouple.

Heat flux and the force density on the surface of elements simulate the heat movement source on the body and across its volume mesh density plays a vital role an analyzing a model by using the FEM (finite element method) [1]. The arc temperature is higher as compared to the M.P (melting point) of the work piece and the dropping pattern is sharply on the regions that are away from the weld pool. The Figure 3 illustrates the graphical cooling pattern of the work piece.

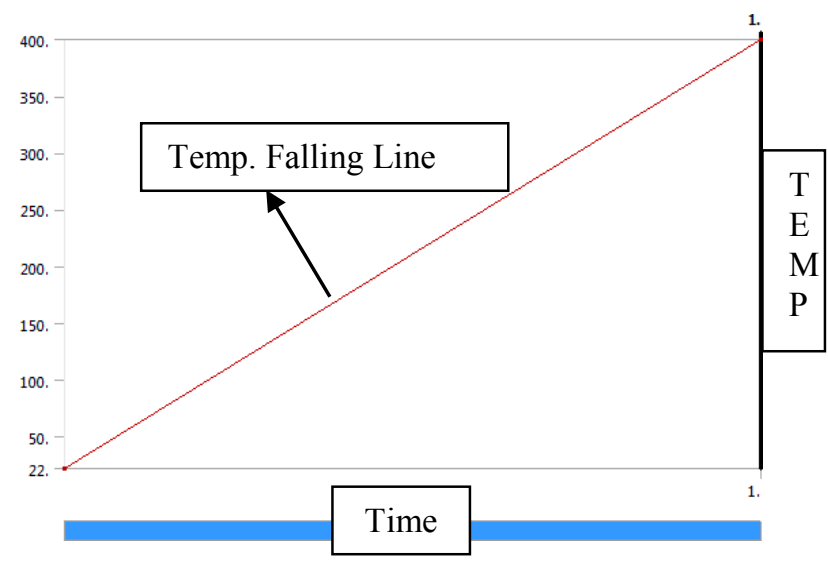

Fig. 3. Cooling graph of the neighboring regions of the weld pool.

From the graph i.e., cooling line shown in red colour it is evident that the fall in temperature is very rapid (Linearly) and the regions of the base metal that are away from the weld pool (neighbouring to weld bead) cools quite rapidly. The initial temperature was $400^{\circ} \mathrm{C}$ and it cools to $22^{0} \mathrm{C}$ room temperature in a very short interval of time. The temperature of HAZ falls very slowly as compared to its neighbouring regions.

\section{Literature Review}

Since the Atomization of SMAW i.e., shielded metal arc welding is limited only to a very limited extent or no automization has been done yet therefore this type of welding is primarily known as Manual welding. This work has been done in order to convert this manual (SMAW) welding into Robotized or automated type of welding. Thus in this regard a six axis articulated PUMA type robot has been used whose manipulator arm has been developed by ARISTO TM. Thus in order to improve the weld quality in a long run (in further trials) it is quite necessary to accumulate the necessary data of the weld quality in an arbitrary run so as to have an idea of the quality of weld in terms of stresses developed on the weld bead while applying a force. Thus the quality of weld could be reached to our satisfaction levels in the subsequent weld trials by controlling the parameters like current, vibrations etc. Due to its enormous applications and easy operations at remote locations (transportations) the versatility of SMAW increases thereby enhancing its significance. The use of SMAW process can be seen both in manufacturing and repairing processes, the quality of weld mainly rely on the skills of the labor $[2,3]$. The population of India is very high also unemployment is at its peak thus we have to make a balance between the automation and the unemployment. Some of the employment / jobs like welding needs automation as it may be life threatening in some circumstances (cases). The other reasons for its automizations is that it is a repetitive kind of work that does not let the people to utilize their brain capacity / potential in other productive tasks. An automatic SMAW welding system have been developed with the help of a robotic Arm that does motion as per the input given with the help of programming, such type of use of the robots proved very beneficial to disengage the work force from doing the repetitive and hazardous job of welding. The quality of weld is inspected NDT, but to save time and cost FEM analysis of the welded joint has been done so as to improve the weld quality in subsequent runs, and the parameters are being monitored with the help of sensors. Many weld processes were inspected with the help of implementing the statistical approaches. Online monitoring and controlling the welding parameters is also very essential [4]. Sensors are connected at desired positions so as to get the data while welding is being performed, these data given by sensors have enabled the user to get the ideal parameters values on which welding depends. These parameters that are required to be taken care of for welding processes are current, arc voltage, electrode consumption rate, welding speed, angle between the electrode and work piece, travelling angle all of the above mentioned parameters are seldom relied upon the worker's skill and its ergonomic conditions. Diversions in these parameters as discussed above may be responsible to have variations in the graphs [5]. Mechanical, chemical and electrical properties also give variations on the arc welding like depth of penetration, temperature of weld pool, width of heat affected zone etc [6]. The SMAW weld processes generally having the value of energy intake higher and lower value of thermal efficiency [7].

\section{Analysis and Modelling procedure}

Properties of the filler metal/weld metal (WM), work piece/base metal (BM) and HAZ or Heat Affected Zone are temperature dependent. The improper knowledge of material properties leads to the dilemma in regard to WM and HAZ, that the thermal properties are considered to be equal to the BM during the analysis [8].

The assumptions are made during the thermal analysis are as follows:

- All of the thermal properties are temperature- dependent (a function of temperature).

- Cooling is done by Newtonian convection at all the elements except the weld zone.

- Natural convection is responsible for cooling, while the loss in heat due to radiation is not considered (neglected). 
- Effects on the base material due to phase change are considered e.g., change in the enthalpy while a change of phase.

- The heat that travels to the work piece from the electrode arc due to conduction and because of the convection at the boundary it eventually releases the heat

- The simulation of welding in ANSYS has two stages, 1) To calculate the thermal analysis or thermal cycles 2) To do the structural analysis for calculating the stresses. The use of the thermal analysis is to find the distribution of temperatures at the weld zone whereas structural analysis is done so as to analyze the distortions and the involved residual stresses.

\section{FEM Analysis}

In this section the FEM (Finite Element Analysis) has been carried out in order to find different types stresses and strains. These calculations along with their procedures have been discussed in the subsequent sections as follows:

\subsection{Calculation of the shear elastic strain}

The analysis comes under Static Structural type and separate parameters have been taken for its analysis. While calculating the shear elastic strain all the assumptions as mention in the section above are considered.

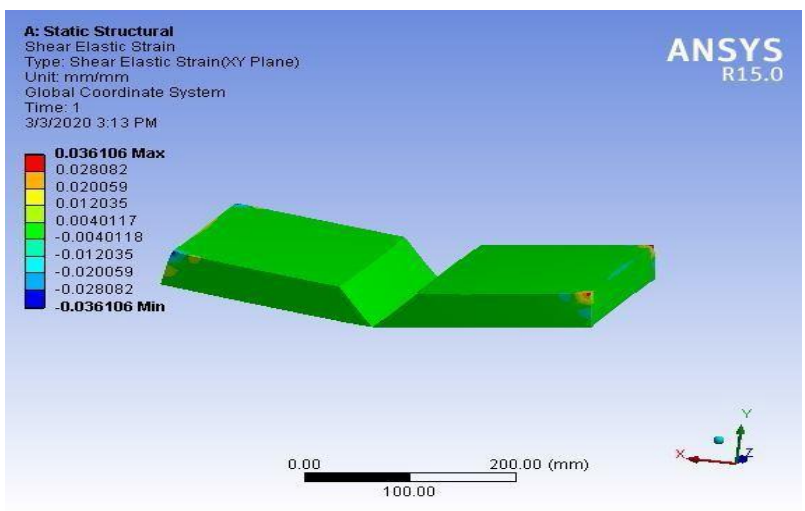

Fig. 4. Shear elastic strain

The points at the corner as the corner points of the VGroove specimen as designed will experience largest value while applying a maximum force of $50 \mathrm{~N}$, as seen from the results obtained by ANSYS R15.0.

$50 \mathrm{~N}$ of force is applied at the welded joint and the values of Shear elastic strain lies in between 0.036 (Max) to -0.036 (Min). It is evident from the values and the fig above that the maximum Shear elastic strain lies at the corner points of the elements and the value corresponds to $0.036106 \mathrm{Mpa}$ i.e., in this case, they are the points experiencing the maximum deformation.

\subsection{Calculation of the normal elastic strain}

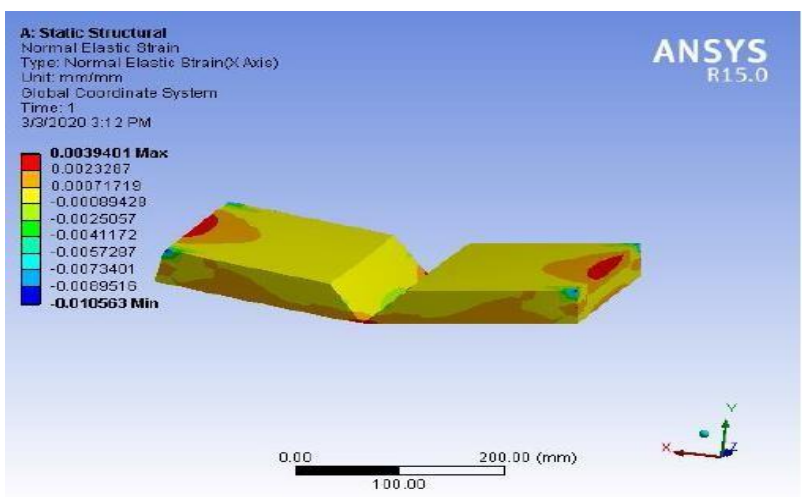

Fig. 5. Normal elastic strain.

The analysis comes under Static Structural type and separate parameters have been taken for its analysis. While calculating the normal elastic strain all the assumptions as mention in the section above are considered. $50 \mathrm{~N}$ of force is applied at the welded joint and the values of normal elastic strain lie in between 0.0039 (Max) to -0.010563 (Min). It is evident from the values and the fig above that the maximum normal elastic strain lies at the middle portion of the edges of the elements and the value corresponds to 0.0039 Mpa i.e., in this case, they are the points experiencing the maximum deformation. The shear elastic strain values are varying at different points on the specimen as the perpendicular load is applied at the corner edges of the specimen. Thus the values are obtained and are shown by the corresponding colour schemes at the corner red colour indicated the maximum value while blue is for representation of minimum values.

\subsection{Calculation of the strain energy}

The analysis comes under Static Structural type and separate parameters (input values) have been taken for finding the value of strain energy (analysis). While calculating the strain energy all the assumptions as mention in the section above are considered. $50 \mathrm{~N}$ of force is applied at the welded joint and the values of strain energy was found to be lying in between 76875 (Max) to 17.512 (Min). It is evident from the values and the fig 5 that the maximum strain energy lies at the edges (Corner points) of the elements and the value corresponds to $78765 \mathrm{~mJ}$ i.e., in this case, they are the points experiencing the maximum strain energy.

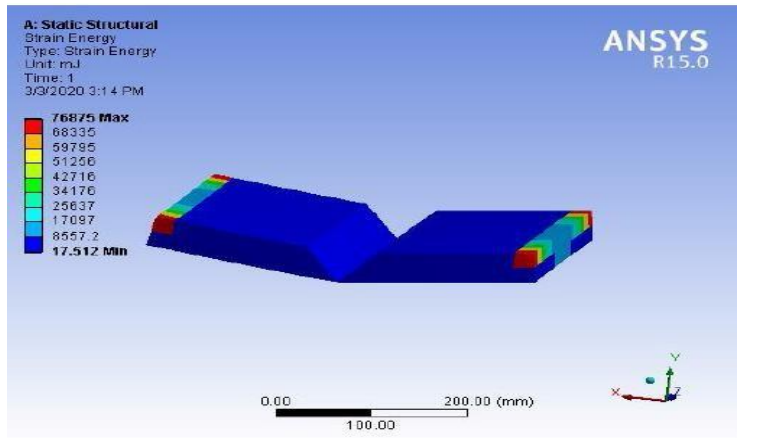

Fig. 6. Calculation of Strain Energy 
The red regions correspond to the regions experiencing the maximum value of the strain energy the yellow and then blue as shown in the figure 6 by the corresponding color schemes.

\subsection{Calculation of the shear stress developed}

The analysis comes under Static Structural type and separate parameters have been taken for its analysis. While calculating the shear stress all the assumptions as mention in the section above are considered. $50 \mathrm{~N}$ of force is applied at the welded joint and the values of shear stress lie in between 2777.4 (Max) to -2777.4 (Min). It is evident from the values and the fig above that the maximum shear stress lies at the edges of the elements and the value corresponds to $2777.4 \mathrm{MPa}$ i.e., in this case, they are the points experiencing the maximum shear stress.

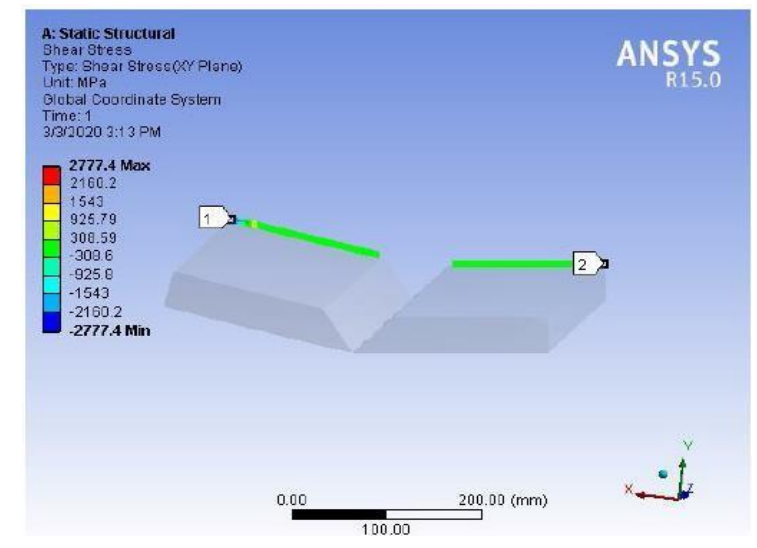

Fig. 7. Calculation of Shear stress

The red regions correspond to the regions experiencing the maximum value of the shear stress the yellow and then blue as shown in the figure by the corresponding colour schemes.

\section{Results and Discussions}

Table 1. Properties of specimen data Mild steel ASTM A 36

\begin{tabular}{|c|c|}
\hline Element & Value \\
\hline Density & $85 \mathrm{e}-009$ tonne $\mathrm{mm}^{-3}$ \\
\hline $\begin{array}{c}\text { Coefficient of } \\
\text { Thermal Expansion }\end{array}$ & $1.2 \mathrm{e}-005 \mathrm{C}^{-1}$ \\
\hline Specific Heat & $4.34 \mathrm{e}+008 \mathrm{MJ}$ tonne $\mathrm{e}^{-1} \mathrm{C}^{-1}$ \\
\hline $\begin{array}{c}\text { Thermal } \\
\text { Conductivity }\end{array}$ & $6.05 \mathrm{e}-002 \mathrm{~W} \mathrm{mm-1C-1}$ \\
\hline Resistivity & $1.7 \mathrm{e}-004 \mathrm{ohm} \mathrm{mm}$ \\
\hline
\end{tabular}

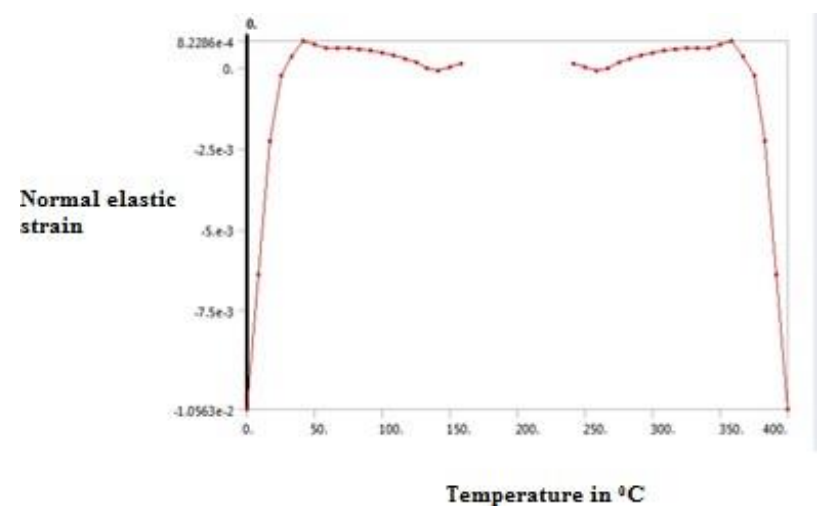

Fig. 8. Strain variation with temperature.

The $\mathrm{Y}$ axis represents to the elastic strain while $\mathrm{X}$ axis is the temperature in ${ }^{\circ} \mathrm{C}$. As evident from the graph as taken from the ANSYS R15.0 the variation is identical for a given range of temperatures i.e., from temperature $0^{\circ} \mathrm{C}$ to $150^{\circ} \mathrm{C}$ and also from $200^{\circ} \mathrm{C}$ to $400^{\circ} \mathrm{C}$. The red line shows the fashion in which these values vary as per the variation in temperature.

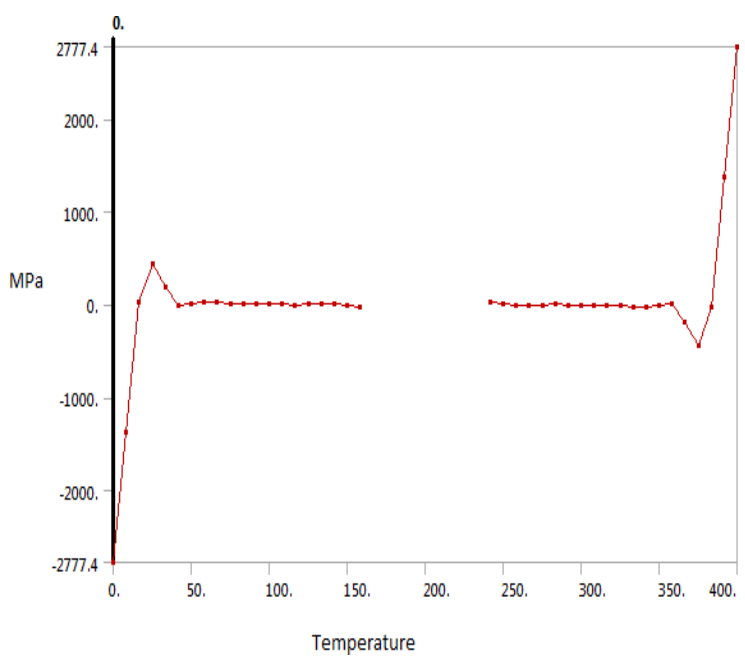

Fig. 9. Graph of Shear stress vs Temperature in ${ }^{0} \mathrm{C}$

\section{Conclusion}

The temperature of the weld pool taken for analysis is $400^{\circ} \mathrm{C}$ and the material of the specimen is Mild steel ASTM A 36 for welding and its coordinating filler material AWS A5.1 E 6013 were chosen in this study. The specimen size was $30 \times 150 \times 9 \mathrm{~mm} 3$ thickness. Welding current was set to $90 \mathrm{~A}$ with welding speed $27 \mathrm{~mm} / \mathrm{sec}$.

- Maximum Shear elastic strain lies at the corner points of the elements and the value corresponds to $0.036106 \mathrm{MPa}$ i.e., in this case, they are the points experiencing the maximum deformation.

- The maximum normal elastic strain lies at the middle portion of the edges of the elements and the value corresponds to $0.0039 \mathrm{MPa}$ i.e., in this case, they are the points experiencing the maximum deformation.

- It is evident from the values and the fig above that the maximum strain energy lies at the edges of the elements and the value corresponds to $78765 \mathrm{~mJ}$. 
- Maximum shear stress lies at the edges of the elements and the value corresponds to $2777.4 \mathrm{MPa}$.

\section{References}

1. L. Yajiyang, W. Juan, C. Maoai, S. Xiaoqin., Bull. Mater. Sci. 27, 2 (2004)

2. P.J. Modenesi, R.C. de Avelar., J. Mat. Pr. Tech. 86, 1-3, (1999)

3. R.J. Sacks., In Ess. of Wel. Benn. Pub. Co. 36, 234-289, (1984)

4. R.H. Lin, G.W. Fisher., Pr. of Sec. Intl. Con. on Mach. Lrng. \& Cbrmtcs., 5, 1, (1994)

5. C.S Wu, D. Rehfeldt Am. Wel. Soc. \& the Wel. Res. Cou, 5, 15, (2001)

6. S.W. Wen, P. Hilton, D.C.J Farrugia., J. Mat. Pr. Tech. 119, 1-3, (2001)

7. R.R. Unocic, J.N. DuPont Mett. \& Mat. Transc. 35, 143-152 (2004)

8. Wu, S. Syngellakis, B.G. Mellor, Pr. of the $7^{\text {th }}$ Post. Con. in Engg. Mat. 37-38 (2001) 